\title{
Conceptualizing Indicators for Children in Diverse Contexts and Particular Circumstances, Challenges and Constraints
}

\author{
Elizabeth Fernandez
}

Accepted: 8 September 2011 / Published online: 20 September 2011

(C) Springer Science+Business Media B.V. 2011

A major concern of contemporary social policy is to improve outcomes for children and young people. Considerable effort is invested at international, national and local levels to identify needs and monitor outcomes. Integral to these efforts has been emerging conceptualisations of children's well-being and the construction of indicators to measure children's well-being. Indicators are being used strategically to communicate about patterns of optimal childhood, monitor and track child outcomes, inform policy and formulate agendas for promoting child well-being. Theoretical and ideological advances, policy demands and methodological refinements have shaped the indicator development and child well-being agenda (Ben-Arieh 2008).

Central to the advances in development of indicators of child well-being have been the various discourses that underpin contemporary understandings of childhood. New conceptualisations of childhood have challenged traditional explanations of childhood and moved the focus from viewing the child as being in transition towards adulthood (well becoming) towards understanding children's present lives (well-being), and towards consideration of 'quality of life' issues for children. The importance of understanding children in terms of the present as both 'being' and 'becoming' is being reinforced (Huebner 2004; Stainton Rogers and Stainton Rogers 1992; Walkerdine 2009). Attempts to reframe childhood and child well-being have also seen challenges to the 'needs' discourse and a shift in orientation to a 'rights' discourse which acknowledges children as 'social actors' and their agency and entitlement to have a voice in decisions and knowledge building about them (Woodhead 1997; Prout 2005; Qvortrup 2004). These discourses, and the developments underpinned by them, have had further impetus from the United Nations Convention on the Rights of the Child (UNCRC), (UN 1989) a normative framework for child well-being which place children's rights in the context of human rights. Its core principle 'best interests of the child' calls for a child focus and strengthens children's roles as citizens in their own right.

E. Fernandez $(\square)$

School of Social Sciences and International Studies, University of New South Wales, Sydney,

New South Wales, Australia

e-mail: e.fernandez@unsw.edu.au 
In line with increasing awareness of children's agency as active individuals with potential to create their reality, there is growing recognition that the perspectives of children and young people are critical to the establishment of policies and indicators that are sensitive to, and reflective of their needs and priorities, and respectful of their ability to interpret their current lives to others (Prout 2001; Hill 1999; Fernandez 2011).

The measurement of child well-being has assumed increasing importance. The impetus for measuring well-being also reflects a convergence of theoretical developments and policy imperatives. In the methodological field Ben-Arieh (2010) highlights significant directions such as a focus on the child as the unit of study, incorporation of child-centred indicators as distinct from family and community driven indicators and, increasing use of administrative data as a potent source of indicator development. The measurement of child well-being has presented major challenges ranging from concerns about measures that are preoccupied with 'deficits' to issues around lack of consensus on definitions and indicators of child well-being among professionals and policy makers (Wulczyn et al. 2005). The field has undergone a paradigm shift towards incorporating strengths and competencies of children, a trend reflected in the use of concepts such as 'positive development', 'youth assets', 'resilience and protective factors' which have gained currency in this field and triggered a broader focus on children's positive development and quality of life.

Additionally, current theorising and indicator development supports the notion that child well-being is the outcome of interaction between a child and the environment of family, community and society, a perspective derived from Bronfrenbrenner's (1979) ecological approach which encapsulates a transactional, multidimensional and dynamic conceptualising of children's well-being.

The acknowledgement of neighbourhoods and communities as contexts for children's well-being and the needs of service delivery and program development at these levels has triggered promising efforts to develop indicators at regional and local levels to mirror the differentiated values, contexts and priorities of these levels (Ben-Arieh 2010)

A further significant step in the development of indicators has been the emerging emphasis on subjective well-being prompted by a recognition that objective measures of well-being need to be complemented by a subjective dimension-one that captures the views of children and young people and conveys feelings and perceptions of their lives and aspirations. How children think and feel about their lives is essential to understanding well-being in any society that grants importance not just to the opinions of experts. A number of theoretical traditions have contributed to understanding subjective well-being, a measure of quality of life of an individual. Bradshaw et al. (2010) address the important issue of children's subjective well-being in a substantial body of international work using well established instruments in surveys.

This overview of trends and emerging priorities signifies an evolving field. Turning to the contents of this issue the papers span the challenges, constraints and opportunities confronting efforts to progress the well-being of children and youth in different contexts. This collection represents a contribution to expanding the knowledge base in this growing field. 
In the first article Ferran Casas examines the theoretical and normative advancements that support the view that perspectives of children are integral to the establishment of policies that are responsive to their needs. The author tracks the indicator movement and the debates around articulating objective and subjective indicators of personal well-being. He draws attention to the limited research in the area of child and adolescent subjective well-being, and importantly, makes a strong case for research and knowledge building derived from perceptions and evaluations by children and young people to balance adult accounts that have hitherto dominated the field and marginalised the agency that children can bring to decisions and policies affecting their lives. Emerging avenues for eliciting children's views that can feed into indicator development, noted by the author, include children's perceptions of family, neighbourhood, school, peer relationships, living environments and use of audiovisual technologies and social media. Casas further notes that increasing international interest in children's social participation presents the opportunity to engage children in co-construction of indicators of subjective well-being.

Policies and programs concerned with addressing the well-being of children and young people have increasingly advocated a social inclusion approach and a greater voice for young people in research and practice. In the next article, through the lens of three evaluation case studies from the U.K. and Nepal, Vicky Johnson discusses child participation in evaluating services and interventions, and the factors that impinge on children's opportunities to exercise agency in selected settings. The case studies offer valuable insights into the potential of different organisational contexts and models in facilitating increased child participation. Based on a well argued rationale the author draws on ecological theories to construct the 'Change-scape model', a framework through which she highlights the contextual and structural issues that promote or inhibit the participatory evaluation process. Arguing that children's participation can potentially constitute a transformative tool, the article cites examples of change in terms of developmental benefits to the children and young people, changes in program approaches, inclusion of children in governance structures and policy changes facilitated by 'champions for children'. The article offers informative material on child participation contributing to an expanding area of cross national research.

In the context of growing demand for organisations to measure and communicate regionally as well as globally on the impact of their programmes Isabelle Carboni and Nathan Morrow present a compendium of indicators focused on a core set of child well-being outcomes. Employing a three tiered process to select from a menu of proposed general indicators, program staff in specific locations/programs are empowered to choose indicators appropriate to their regional context that measure their contribution to core child well-being outcomes. The authors' analyses of the implementation of the piloting of this framework illuminates the creative strategies and participatory processes used to identify children's and community definitions of well-being in diverse contexts. Combining the lens of an ecological approach which recognises children's interactions with family, community and policy environments and a life course perspective attuned to the vulnerabilities of children and young people of different ages, the authors report on a participatory process which explored children's and community perceptions of well-being and how the compendium of 
indicators might guide flexible indicator selection as well as build understanding and ownership of the indicators chosen by program staff.

The article by Peter Scales presents evidence from research across five countries to support the applicability of the Developmental Assets Profile (DAP) in a range of cross national and cross cultural contexts, and with socioeconominally diverse youth. Grounded in theory and research on positive youth development and an ecological systems approach, this framework attempts to capture and measure progressive change over time in developmental assets including young people's experience of support, empowerment, boundaries and expectations, use of time, commitment to learning, social competencies, and positive values and identity. The article offers an insightful account of the methodological challenges of conducting cross cultural and culture sensitive research. The cultural constructions that influence youth reporting of self perceptions in particular cultures and the nuances of operationalising developmental concepts in specific domains cross culturally are usefully highlighted. Overall the results indicate the potential of the instrument to capture indicators of youth well-being and promote awareness and advocacy for positive youth development among practitioners and policy makers.

Refugee children confront adverse levels of disruption, dislocation and victimisation that threaten their psychological well-being in the post migration and settlement process. In the next article Colleen McFarlane, Ida Kaplan and Jeanette Lawrence draw on research conducted in Victoria, Australia to isolate key indicator domains of well-being: psychological well-being, family well-being, connections to social groups and community, and positive expressions of well-being. The development of this framework of outcome indicator domains in this distinctive field is grounded in data emanating from interviews conducted with refugee children and young people, parents and professionals. Through rich qualitative accounts from children and young people, families and professionals the article captures expressions of grief, sadness, emotional distress and isolation resulting from multiple losses and traumatic experiences. Besides capturing a range of areas of adaptive functioning at individual, family and relational levels, the authors draw attention to the influence of contextual variables that mediate positive outcomes and highlight the implications for indicator development for the purpose of delivering interventions and framing policy.

In the next article Sonia Velazquez and Alan Dettlaf attempt to build a framework for the advancement of the well-being of migrant children in the U.S. Drawing on national data, legislative and policy trends and literature the authors draw attention to the circumstances that compound immigrant families' emotional, social and economic security and in turn jeopardise child outcomes. Inherent stressors arising from high levels of poverty, restricted access to preventative and supportitive services, less than optimal health care, instability from changing family composition and caretaking arrangements and sequels of pre and post migration traumas are highlighted. Attention is also drawn to the particular vulnerabilities children, young people and parents experience in state child protection and care systems in the context of reunification and legal permanency as they age out of care. Encouragingly the dialogue and collaboration initiated with professionals and policy makers in different 
disciplines in wide ranging contexts including academics, child welfare systems, national and international immigration representatives, legal practice and advocacy organisations including the Annie Casey Foundation, has culminated in a national coalition to articulate a research and policy agenda to secure and promote the rights of immigrant children and advance indicator development in this field.

In the next article Wendy O'Brien examines the theme of social exclusion and its impact with respect to children with sexualised behaviours and their access to therapeutic services in Australia. In her overview of the international literature on childhood abuse, unstable family environments, socio-economic disadvantage, exposure to caregiver drug and alcohol misuse, developmental delay are prominent in the histories of children who come to the attention of services for problem sexual behaviours. The author outlines urban and rural contexts of disadvantage that pose risks to childhood sexual problem behaviours and circumscribe service responses. She pinpoints a dearth of specialised services to children and families and barriers that disadvantaged families confront in accessing services. Reinforcing the importance of ecological models of therapeutic intervention which emphasise family and community involvement in the rehabilitation of children and adolescents with sexualised behaviour the author advocates a research and policy agenda that prioritises 'contextually specific tertiary responses' to children in this area of need.

A child rights approach to considering children's evidence in court decision making and the acknowledgement of children's agency in the context of Family Court decisions relating to divorce, residence and contact arrangements are explored in the next article by Wendy Foote. Drawing on a larger qualitative study the author employs three cases from Family Law hearings involving conflicting child abuse allegations to illuminate how judges worked actively to discern the voice of the child in the context of conflicting evidence. The author tracks the judicial decision making to illuminate the process of distinguishing the child's voice through a careful analysis of the evidence from competing sources in a litigation environment of parental dispute. Taking children's rights seriously requires a professional environment committed to a paradigm that centralises the voice of the child and acknowledges children's ability to provide information about their lives is a strong message from this paper.

In the next paper Jung-Sook Lee makes some inroads into exploring the relationship between poverty and children's outcomes. Drawing on longitudinal data from the Longitudinal Study of Australian Children, the author examines effects of persistent poverty on children's physical, socio-emotional and learning outcomes. Profiles of the families in the 'persistently poor' groups studied indicated a preponderance of young mothers, parents with low educational attainment, children from non-English speaking backgrounds and Indigenous children. Results suggest that children in the 'persistently poor' group achieve lower socio-emotional and learning outcomes, compared to children in the 'never poor' group. From her analyses based on different thresholds of poverty status (bottom $10 \%$ of the income ladder compared to bottom $20 \%$ of the ladder) which revealed consistently low child outcomes, the author asserts that parental income below the $20^{\text {th }}$ percentile is inadequate to provide optimal environments for the healthy development of children. Concerted efforts to put in place supportive and 
supplemental services for families affected by poverty to enhance outcomes for children is advocated.

The final paper by Elizabeth Fernandez and Jung Sook Lee reports research into the factors associated with the reunification of children with their birth families following a period of protective care. The study employs the multidimensional North Carolina Family Assessment Scale (NCFAS-R) which conceptualises child and family functioning into seven domains (Environment, Parental capabilities, Family Interactions, Family Safety, Child wellbeing, Ambivalence and Readiness for Reunification). Their analyses identifying significant predictors of children's probability of experiencing different pathways in their placement trajectories using Latent Profile Analysis illustrate the influence of multidimensional indicators on reunification outcomes for children. Results indicate that families with low average scores on domains of parental capabilities, family interactions and child wellbeing had a $73 \%$ lower rate of reunification. The authors draw attention to the need to intervene on multiple fronts to offer supports to families and children pre reunification.

Acknowledgement The papers in this collection emanate from the Second International Conference of the Society for Child Indicators held in Sydney in November 2009. I would like to acknowledge all the authors for contributing their valuable work to this special issue of CIR. I extend thanks to the reviewers for their expertise in providing constructive editorial comments to authors to enhance the coherence of their material. Thanks are also due to Asher Benarieh and colleagues at Springer for facilitating the publication of this special issue.

\section{References}

Ben-Arieh, A. (2008). The child indicators movement: past, present and future. Child Indicators Research, $1,3-16$.

Ben-Arieh, A. (2010). Developing indicators for child well-being in a changing context. In C. McAuley \& W. Rose (Eds.), Child well-being: Understanding children's lives. London: Jessica Kingsley Publications.

Bradshaw, J., Rees, G., Keung, A., \& Goswami, H. (2010). The subjective well-being of children. In C. McAuley \& W. Rose (Eds.), Child well-being: Understanding children's lives. London: Jessica Kingsley Publications.

Bronfenbrenner, U. (1979). The ecology of human development: Experiments by nature and design. Cambridge: Harvard University Press.

Fernandez, E. (2011). Child inclusive research, policy and practice. Children and Youth Services Review, 33(4), 487-489.

Hill, M. (1999). What's the problem? Who can help? The perspectives of children and young people on their well-being and on helping professionals. Journal of Social Work Practice, 13(2), 135-145.

Huebner, E. S. (2004). Research on assessment of life satisfaction of children and adolescents. Social Indicators Research, 66, 3-33.

Prout, A. (2001). Representing children: reflections on the children 5-16 programme. Children and Society, 15, 193-201.

Prout, A. (2005). The future of childhood: Towards the interdisciplinary study of children. London: Falmer Press.

Qvortrup, J. (2004). Childhood matters: An introduction. In J. Qvortrup, M. Bardy, G. Sgritta, \& H. Wintersberger (Eds.), Childhood matters: Social theory, practice and politics. Aldershot: Avebury.

Stainton Rogers, W., \& Stainton Rogers, R. R. (1992). Stories of childhood: Shifting agendas of child concerns. Hemel Hempstead: Harvester Wheatsheaf.

United Nations (UN) (1989). United nations Convention on the Rights of the Child, http://www2ohchr. org/english/law/crc.htm, Accessed April 2010. 
Walkerdine, V. (2009). Developmental psychology and the study of childhood. In M. J. Kehily (Ed.), An introduction to childhood studies (2nd ed.). Maidenhead: Open University Press.

Woodhead, M. (1997). Psychology and the cultural construction of children's needs. In A. James \& A. Prout (Eds.), Constructing and reconstructing childhood: Contemporary issues in the sociological study of childhood. London: Palmer Press.

Wulczyn, F., Barth, R. P., Yuan, Y. T., Harden, B. J., \& Landsverk, J. (2005). Beyond common sense: Child welfare and well-being, and the evidence for policy reform. New Brunswick: Aldine Transaction. 